\title{
0106 INJURY SURVEILLANCE IN TARIJA, BOLIVIA
}

D Zavala* Correspondence: Ponce School of Medicine, P.O. Box 7004 Ponce, 00732-7004, Puerto Rico

10.1136/ip.2010.029215.106

An injury surveillance system has been established at Hospital San Juan de Dios in November 2009, in the city of Tarija, Bolivia. This is the main hospital for the city that received close to $90 \%$ of all injury cases that require emergency service and/or hospitalisation. Therefore the data collected at this hospital can well reflect the occurrence of injuries in the city of approximately 171000 people. Based on a 2003 health survey, $68.6 \%$ of those interviewed reported a previous incident of interpersonal violence.

We report on an analysis of the first 9 months of data collection (December 2009-August 2010) for the three most frequent injuries treated at the hospital emergency department: intentional injuries such as interpersonal violence, child and elderly abuse, youth violence, self-inflicted violence and road traffic injuries. 